\title{
Percepciones de las transformaciones territoriales: un estudio comparativo entre la Comuna 13 en Medellín y Barrio El Carmel en Barcelona
}

\author{
Perceptions of territorial transformations: a comparative study between Commune 13 in \\ Medellin and Barrio El Carmel in Barcelona
}

\begin{abstract}
Enid Carrillo $^{a}$, Julián Escobar $^{b}$
Abstract:

This research presents an analysis of the perceptions about the territorial transformations in two neighborhoods of similar contexts: the case of Comuna 13 in Medellín and the El Carmel neighborhood in Barcelona. This approach is tackled through in-depth interviews that allow rescuing the voices of the inhabitants of both spaces and the way in which they interpret and socialize the territorial changes around them. The comparison is proposed based on the similarities that arise from globalization and its effects at the city and neighborhood levels. It is analyzed how similar phenomena can occur in geographically distant territories and the perceptions of the inhabitants are framed in the phenomena born from the transformation of the territory in both places.
\end{abstract}

\section{Keywords:}

Territory. perceptions. globalization. Space turistificación

\section{Resumen:}

El presente trabajo analiza las percepciones sobre las transformaciones territoriales en dos barrios de contextos similares: el caso de la Comuna 13 en Medellín y el barrio El Carmel en Barcelona. Este acercamiento se aborda mediante entrevistas a profundidad que permiten rescatar las voces de los habitantes de ambos espacios y la forma en que interpretan y socializan los cambios territoriales a su alrededor. La comparación se plantea a propósito de las similitudes que nacen de la globalización y sus efectos a nivel de ciudad y barrial. El artículo analiza cómo pueden darse fenómenos similares en territorios geográficamente distantes y las percepciones de los habitantes se enmarcan en los fenómenos nacidos de la transformación del territorio en ambos lugares.

\section{Palabras Clave:}

Territorio. Percepciones. Globalización. Turistificación del espacio

\section{Introducción a la relación entre percepción y territorio}

En los últimos años, la percepción ha emergido como una categoría analítica que interesa a diversos campos del conocimiento. El auge de las encuestas de percepción y de las aproximaciones fenomenológicas al estudio del territorio confirma la necesidad de mirar al sujeto como el informador primario de la realidad. Por ello, actualmente la producción científica en torno a esta categoría y su relación con el territorio se ha diversificado y posibilitado el diálogo entre diferentes disciplinas (Serrano, 2015).

La percepción resulta una categoría relevante para el entendimiento de la relación entre los sujetos y el medio
(Briceño y Scheuren, 2005) y es entendida como "una respuesta de los sentidos a los estímulos externos, una actividad propositiva en la cual son seleccionados y registrados ciertos fenómenos y, en cambio, otros son bloqueados" (Tuan citado en Zenteno, 2018: 105). En el contexto de la percepción del territorio, existe un estímulo que desencadena el proceso de percepción y que direcciona o condiciona la manera en la que es apreciada la realidad geográfica.

Los estudios referidos a la percepción tienen su origen en la década de los 60 en el contexto de la Escuela de Chicago y fue originalmente adoptada para estudios urbanos y ambientales. En ese tenor destaca el trabajo de Kevin Lynch (2015) sobre la imagen de la ciudad y 
posteriormente, comienza a nutrirse de lo propuesto por la psicología ambiental en trabajos de Canter y Holah an (quienes inician su producción teórica en la década de los setenta) y la geografía de la percepción. Estas reivindicaciones en los estudios del territorio obedecen a la necesidad de una nueva concepción centrada en la experiencia, que permitiera profundizar en los efectos de los cambios territoriales en los sujetos que lo habitan.

En ese sentido, surge un replanteamiento de la idea del territorio, que más allá de la concepción geográfica, fue llenándose cada vez más de contenido social, pues "EI territorio es un espacio apropiado por los grupos sociales, para fijarse en él, asegurar su supervivencia, construir viviendas y rutas, explotar productos, delimitar dominios" (Capel, 2016: 7). Esta noción del territorio lo ubica también como un espacio para la lucha y el conflicto, pues en él están presentes el contexto cultural, el lenguaje y la estructura social y los intercambios comerciales en interacciones que posibilitan el ejercicio de poder.

Esta visión del territorio transgrede lo estrictamente morfológico y lo considera un escenario en el que se dan procesos de diversas naturalezas que, como lo menciona Haesbaert (2007), genera diversas nociones que pueden ser agrupadas en tres vertientes básicas:

[...] Política (referida a las relaciones espacio-poder en general) o jurídica-política (relativa también a todas las relaciones espacio poder institucionalizadas. [...] Cultural (muchas veces culturalista) o Simbólico-cultural: prioriza la dimensión simbólica y más subjetiva, en la que el territorio es visto, sobre todo, como el producto de la apropiación/valoración simbólica de un grupo en relación con su espacio vivido [...] Económica (con frecuencia economicista): menos difundida, destaca la dimensión espacial de las relaciones económicas, el territorio como fuente de recursos o incorporado al conflicto entre clases sociales y en la relación capital-trabajo como producto de la división "territorial" del trabajo... (Haesbaert, 2007: 35).

Estas vertientes permiten resignificar la idea del territorio en un concepto que rebasa la noción espacial y permite reconocerlo como generador de procesos de tipo político, económico y cultural, en el que están implícitas las relaciones sociales, la construcción de grupos y las diferencias económicas, culturales e ideológicas. Es por ello que el territorio se ha comenzado a interpretar como una construcción y, como ha quedado establecido por Capel (2016), si se quiere entender realmente la acción del hombre sobre el medio terrestre, se tiene que comprender la mente y la forma en que en ella se genera la percepción del entorno.

Dadas estas discusiones, han surgido aproximaciones al análisis territorial, como la geografía de la percepción. Al respecto de las cuales, el geógrafo Horacio Capel recupera los estudios más relevantes originados en la década de 1970, entre los que se encuentran análisis de percepción de la zona de riesgo; percepción del clima, del conjunto de riesgos naturales, de eventos catastróficos producidos por la acción humana y de percepción del paisaje.

Estos acercamientos consideran de forma inherente la idea de transformación territorial, pues se entiende que el territorio es dinámico y cambia, a veces de forma natural y, otras, como resultado de la acción humana, Io cual tiene un impacto en los sujetos que lo habitan, lo socializan y recrean en el complejo proceso de la percepción.

\section{Transformaciones en el territorio, transformaciones en la percepción}

La intensidad de los movimientos migratorios y de los flujos de capitales y mercancías ha reconfigurado la relación entre las escalas global y local. La explotación de territorios con riquezas naturales o características turísticas y patrimoniales, las políticas neoliberales y los procesos de descentralización han sumado a la creación de nuevas concepciones sobre el territorio (Capel, 2016).

En algún punto, la discusión sobre el territorio se centraba en considerar su "materialidad fija"i y no se asociaba con él la noción del movimiento. Pero al ser susceptible de ser intervenido, el territorio, en su base material, permite acceder a él para delimitarlo, construirlo, destruirlo y transformarlo, y constituye espacio relacional, productor y receptor de cambios.

Como lo reconoce Rayón (2018), los efectos de la globalización devienen en problemas generalizados (identificables a escala territorial) como la degradación del medio ambiente, la especulación del capital, la importancia de los medios de comunicación, el aumen to de la urbanización y de los movimientos migratorios, la aparición de una cultura uniformada (muchas veces de manera forzada) con los valores capitalistas de la American way of life.

En este sentido, es importante identificar cómo y desde dónde se originan las transformaciones en el territorio, pues estas modificaciones pueden surgir como iniciativa de los propios habitantes, desde el Estado, de los grupos disidentes o de los actores sociales activos que han irrumpido en el espacio para modificarlo. Estas intervenciones tienen efectos positivos o negativos que sobreviven a la transformación material y permanecen en la cultura a través del tiempo.

Los cambios que ocurren en el territorio se dan de formas distintas: algunos ocurren a nivel de la forma geográfica (que además es importante saber desde donde se gestan, si desde el Estado, la sociedad civil, el sector privado o la propia naturaleza). Se necesita 
profundizar en ello, ubicar los fenómenos que transforman el territorio: el turismo, los planes a gran escala, los proyectos urbanísticos o cualquier actu ación que suponga una discontinuidad en el territorio material y simbólico para comprender los efectos en los sujetos que lo habitan.

Pues como se ha observado, el turismo es un proceso que modifica las formas de habitar la ciudad (Hiernaux y González, 2014) y ha devenido en un fenómeno espacial conocido como gentrificación, que refiere a procesos de renovación urbana de zonas estratégicas (para el desarrollo del turismo) en una ciudad, como producto del arribo de sujetos de estratos altos y medios que provocan el desplazamiento de sectores pobres que residen en ellos (Rojas, 2016).

Esta dinámica impuesta sobre el territorio provoca, además de la expulsión de residentes, el encarecimiento del costo del suelo y el surgimiento de problemas relacionados con la forma urbana de las zonas de ciudad que se están gentrificando. Si bien, la gentrificación es un proceso de origen multivariado, ocurre como una intervención a escala del territorio, que lo mercantiliza y lo transforma, cambiando con ello, todos los elementos físicos y simbólicos que subyacen en el territorio.

Como lo refieren estudios previos, "la transformación territorial más profunda que se está produciendo en el siglo XXI está asociada al surgimiento de la ciudad contemporánea dispersa, de escala regional y complejidad desconocida previamente" (Vergara y De las Rivas, 2004: 273), en la que la comercialización del espacio y la politización del mismo están generando nuevas formas de gestionare intervenir el territorio.

Al respecto, autores como Bauman (2003), Harvey (2012) y Sassen (2001) trabajan la idea del territorio vista desde el proceso de globalización en el que subrayan la relación entre el territorio, la economía global y el movimiento de capital. Bauman (2003) señala un fenómeno particular, en el que el territorio ha perdido su poder en los intercambios económicos y se ha vu elto menos necesario para el movimiento de capital, por lo que lo considera como "líquido". A su vez, Saskia Sassen reconoce impactos en el territorio derivados de las dinámicas financieras actuales que devienen en una discontinuidad espacial en el territorio.

Para Harvey (2012), existe una geografía cambiante en el modelo capitalista que transforma el territorio a través de intervenciones a gran escala. Este proceso se denomina "destrucción creativa del territorio" y da cuenta de las modificaciones territoriales nacidas de los intereses del capitalismo y los devastadores estragos que tiene a nivel territorial.

A esta postura se agrega el trabajo de Rogério Haesbaert (2007), que propone a la desterritorialización como un concepto que describe el desarraigo del territorio y el surgimiento de nuevos fenómenos a nivel territorial, en los que el sujeto reproduce su vida material, pero permanece arraigado a un territorio simbólico.

En este sentido, como consecuencia de lo anterior, Arreola y Saldívar (2017) señalan que existen dos fenómenos relevantes al respecto del territorio en el contexto actual: la transformación en el papel del Estado y todos sus referentes territoriales y el papel de la tecnología en el acortamiento de las distancias que facilitó una nueva articulación entre escalas local y global.

Las transformaciones territoriales contemporáneas requieren intervenciones para modificar al territorio (Gorenstein, 2015) y al modificarse se cambia todo lo que se genera dentro de él. Las transformaciones siempre tienen impactos en el imaginario de los habitantes y esas percepciones sobreviven a la propia materialidad del territorio y permanecen en el tiempo a través de la socialización del espacio.

Como lo reflexiona Bauman (2001), el territorio urbano es el campo de batalla de una guerra por el espacio que tiene efectos directos a nivel del vecindario y en los estratos más bajos de la sociedad que, paradójicamente, en el contexto de la globalización, experimentan una territorialidad forzada, es decir, un anclaje al territorio que se vuelve inevitable por la falta de oportunidades y la imposibilidad de gran parte de la población de trascender el territorio.

Esto permite observar cómo los problemas sociales suceden de manera especial y se ubican en un en torno material que no es el mismo para todos, pues el espacio también se ve atravesado por las relaciones de poder, por quienes pueden trascenderlo y quienes no, aquellos destinados a "localizarse" en un territorio para habitarlo, con escasas posibilidades de movilización, receptores de todo aquello que sucede al nivel de su emplazamiento.

\section{Intervenciones territoriales}

El territorio es un escenario en el que están en lucha las relaciones de poder, se hacen visibles allí, pues en él se generan procesos de inclusión y exclusión, disputas espaciales, políticas y simbólicas en las que está en juego el control y la supremacía de un grupo sobre otros. Por ello, los planteamientos hasta aquí expuestos coinciden en una crítica al sistema capitalista, como el responsable de poner en lucha las fuerzas que encuentran en el territorio un campo de batalla.

Frente a esto, surge la necesidad de hacer lecturas críticas sobre lo que sucede en el territorio y repensar si las intervenciones diseñadas desde el Estado tienen que ver con los intereses de quienes los habitan, pues las 
intervenciones territoriales suceden como resultado de la política pública o de la toma de decisiones, que ocurren a nivel urbano y responden a lógicas diversas.

En este sentido, Sonderéguer (2002) subraya que la intervención en el territorio debe dar cuenta de las transformaciones ocurridas en la relación Estadosociedad y en los procesos de territorialización de la economía, lo que implica que cualquier intervención territorial revela el estado de las relaciones sociales y económicas que se emplazan en el territorio.

Como lo reconocen Vergara y de las Rivas (2004) las intervenciones pueden ser simples, pero significativas. Los autores recogen el caso de Namibia y la transformación de las fachadas en el lugar para gen erar mejores relaciones vecinales. Sin embargo, existen casos en los que las disputas por el poder son las responsables de intervenir el territorio, como es el caso de las células del narcotráfico diseminadas en ciertas regiones, la presencia de pandillas o de grupos de control que se apropian del territorio y modifican las prácticas que ocurren dentro de él.

Es por ello que resulta primordial que los investigadores escuchen a los testigos de estas intervenciones para ubicar los efectos nacidos de la metamorfosis del territorio, pues para comprender las concepciones humanas del espacio se debe referir a las relaciones cualitativas entre las cosas y el espacio (Cuenca y Giraldo, 2017).

En este sentido, al hacer una aproximación fenomenológica al estudio de las transformaciones territoriales, se reconoce que el territorio es susceptible de ser narrado. Para ello, se acuña un concepto denominado territorialidad, que es definido como:

La acción de significar un lugar y con ello, proteger, ratificar, defender, marcar, generar y alterar el territorio mediante hábitos, ritos, costumbres, prácticas y usos por un sujeto individual o colectivo. Los otros dos ejes conceptuales que enlazan a la territorialidad son los vínculos de dominio y de poder, y la apropiación vista como forma(s) de vivir y habitar un territorio (Avendaño, 2010: 15).

Es así como la relación del individuo con su espacio encuentra un marco explicativo en la territorialidad, concepto que reivindica el papel del sujeto frente al territorio como el portavoz de los cambios y transformaciones que suceden en él. Esta aproximación da pauta para hacer lecturas de la realidad enmarcadas en la relación material y simbólica entre las personas y su ambiente próximo.

El contexto actual y las reconfiguraciones territoriales en el marco de la globalización dan paso a una serie de fenómenos que parecen multiplicarse a lo largo del globo, que guardan una extraña similitud y que dan cuenta sobre los impactos de la globalización y su reproducción en territorios diversos y apartados unos de los otros.

Frente a tal situación, el presente trabajo recupera dos experiencias de transformaciones territoriales, una en $\mathrm{La}$ Comuna 13 en Medellín, Colombia y, la otra, en el Barrio El Carmelo en Barcelona, España. El foco de la investigación está en indagar en las percepciones que los habitantes de ambos lugares tienen al respecto de estas transformaciones, para reconocer el impacto que tienen las intervenciones territoriales en el habitar de las personas.

\section{Turistificación del espacio}

En las últimas décadas, el turismo se ha constituido como un fenómeno global que ha transformado las ciudades e irrumpido en el territorio a través de estrategias de mercantilización. El interés turístico vuelve al espacio una mercancía, lo que tiene un impacto en la vida de los barrios populares y en las periferias urbanas (Marcús, 2019). Históricamente, el territorio ha funcionado como un soporte material para las actividades humanas, contenedor y generador de prácticas de diversa naturaleza que, al convertirse en una mercancía, afecta cada uno de esos procesos que se ubican en él. En el caso específico del turismo, éste "necesita del espacio y, al mismo tiempo, lo transforma y produce" (Almirón, 2004: 168).

Como actividad económica, el turismo es una fuente de ingresos que contribuye a la transformación de la forma urbana, pero también despoja a una comunidad de su patrimonio material y simbólico y de su calidad de vida y de la singularidad de que la define (Crespi y Mascarilla, 2018).

El proceso de turistificación se da a través de modificaciones en el espacio, estrategias de renovación y rehabilitación y, en algunos casos, a través de dispositivos de limpieza social como la "higienización y sanación" urbanas (Marcús, Mansilla, Boy, Yenes, Arcó, 2019) que devienen en problemas de segregación y gentrificación (blanqueamiento por despojo) de ciertos puntos de la ciudad.

Hoy en día existen múltiples ejemplos de turistificación del espacio alrededor del mundo, como son los casos de Barcelona, Ámsterdam, Venecia, Berlín, Paris, Reikiavik y Los Ángeles y diversas ciudades de economías emergentes, como Ciudad de México, Medellín o Río de Janeiro. Sin embargo, ya en la década de los 90, se registraban reacciones diversas contra los procesos de desposesión, desplazamiento, especulación residencial y explotación laboral en países como España, Malta, Grecia, Francia, México y países de Centro América (Milano, 2018).

Al respecto, Claudio Milano reconoce que la turistificación del espacio se convierte en una categoría 
de análisis relevante para el entendimiento de las dinámicas territoriales a escala global y sus impactos en términos locales, entre los que se ubican: el aumento de alquiler, privatización y congestión de los espacios públicos, disminución del poder adquisitivo de los residentes, precarización del empleo e impacto ambiental.

Por otra parte, resulta imperioso precisar que a la par del turismo, existen otras prácticas como la migración o el desplazamiento forzado, que suelen convivir en un mismo territorio, pero que deben diferenciarse y explicarse desde ópticas particulares, que si bien están relacionadas con el turismo no son dependientes de él.

En el marco de la urbanización capitalista, la comercialización del territorio genera transformaciones $y$, por tanto, impactos en la vida de las personas. Por ello, en esta investigación se reconocen y ubican esos procesos como parte de las dinámicas territoriales de Barcelona y Medellín, y se escudriñan los impactos de la vocación turística de ambas ciudades en la percepción que los habitantes tienen del territorio.

\section{Metodología}

El presente trabajo plantea una comparación entre dos casos relevantes de intervenciones a nivel territorial en el urbanismo contemporáneo: la Comuna 13 en Medellín, Colombia y el Barrio El Carmel en Barcelona, España. Esto para recuperar y analizar las narraciones que los habitantes de ambos sitios hacen de las transformaciones que han experimentado sus lugares.

La herramienta utilizada fue la entrevista semiestructurada, para la que se diseñó un cuestionario guía para el levantamiento de discurso. Se ha seleccionado esta herramienta en virtud de la información que puede aportarse a la narrativa del territorio, pues:

...cuando lo fundamental de una investigación recae sobre el sujeto en su relación con lo social y lo político, la verdad no se ajusta a la objetividad histórica de los hechos, sino a la lógica del discurso de quienes los narran. Se trata de buscar la riqueza de matices en cuanto al modo como se ha producido en los habitantes (Atehortúa, Sánchez y Jiménez, 2009: 119).

Dado lo anterior, este trabajo presenta los testimonios de los habitantes de ambos lugares para visualizar sus percepciones respecto del territorio que habitan. En estos testimonios hay una pluralidad de voces y perfiles que hablan de la diversidad que se da tanto en la Comuna 13 como en el Barrio El Carmel.

Las entrevistas se realizaron en un período de seis meses, en los que se trabajó con actores clave, líderes comunitarios, vecinos y miembros de la sociedad civil organizada. Las preguntas giraron en torno a la vida del barrio, las principales problemáticas a nivel territorial, las intervenciones territoriales, la relación habitante-Estado y la turistificación del espacio, de tal manera que estas mismas categorías pudieran servir como ejes de análisis para ambos casos.

La selección de entrevistados se dio en efecto bola de nieve, a partir de acercamientos en campo con actores clave y sociedad civil organizada.

\section{Escenarios de la transformación: contextos socioterritoriales de la Comuna 13 y Barrio EI Carmel}

La comuna 13 de Medellín se localiza en la periferia noroccidental de la ciudad; actualmente, está poblada por 140 mil habitantes (Alcaldía de Medellín 2018). Durante décadas, Medellín atravesó una época álgida a casusa de la violencia producida por el narcotráfico y las disputas territoriales generadas por actores armados tanto legales (fuerza del Estado) como ilegales (organizaciones guerrilleras y grupos paramilitares) (Aricapa, 2016). Uno de los casos más conocidos, fueron intervenciones militares en la ciudad, específicamente en los barrios 20 de Julio y las Independencias de la comuna 13, operaciones cuyos saldos dejaron a cientos de personas desplazadas y decenas de personas muertas, como fruto de las disputas por la dominación del territorio, que determinaron la forma en la que los ciudadanos vivían y se relacionaban con la autoridad Estatal y paraestatal.

En este sentido, la dominación como lógica de apropiación del territorio llevó a los gobernantes de la ciudad a replantear una política urbana que pudiese frenar el fenómeno de la violencia a través de la transformación física y social del espacio urbano. Para inicios del 2000, tanto Colombia, en general, como la ciudad de Medellín atravesaban por un momento en el que se determinaba un plan de reconfiguración del modelo de país, que apostó por la seguridad como medio dilatador de la inversión extranjera y el desarrollo social a escala regional y nacional.

Ante este panorama y a través del Plan de Desarrollo de ciudad, realizado por la alcaldía "Medellín: Compromiso Ciudadano" (2004-2007), se propuso intervenir los territorios con deudas sociales que habían sido azotados por la violencia y la inseguridad (Alcaldía de Medellín, 2004). Estas intervenciones fueron posibles mediante la transformación del espacio público como eje articulador de una política que buscaba que la ciudadanía se apropiara de las dinámicas territoriales del espacio urbano a través de mecanismos democráticos y participativos. Para ello, fue necesario el planteamiento de varios planes parciales y de presupuesto participativo que buscaban la cohesión entre empresa privada, el Estado y las organizaciones sociales barriales. 
Estas intervenciones se materializaron mediante planes urbanísticos denominados Proyectos Urbanos Integrales (PUI), cuyas estrategias permitieron transformar los territorios periféricos de la ciudad gracias a la inversión Estatal y de la empresa privada en torno a la construcción de parques bibliotecas y el fortalecimiento del sistema de transporte urbano, como lo fue el metrocable, la tecnificación de transportes de los buses articulados, el sistema metro y las escaleras eléctricas en los barrios periféricos y de ladera (especialmente el barrio las Independencias de la Comuna 13). Todas estas intervenciones se realizaron conforme a las políticas administrativas de la ciudad durante los periodos de "La Medellín compromiso ciudadano" y del proyecto: "Medellín más educada" (Alcaldía de Medellín, 2004; 2008).

Estos proyectos, que actuaban como mecanismos de intervención territorial, han beneficiado a una población estimada de 140 mil habitantes. Las trasformaciones territoriales propuestas por la administración 2004-2007, tenían como objetivo la transformación de las prácticas socioterritoriales en la Comuna 13.

Un caso ejemplar fue la construcción del Parque Biblioteca "Presbítero José Luis Arroyabe San Javier", cuyo objetivo fue "quitarle terreno a la violencia y abrirle espacio al arte en todas sus formas de expresión" (Rincón, 2015: 49). En este sentido, el Parque Biblioteca permitía intervenir el territorio desde la infraestructura para producir lugares de encuentro ciudadano, como forma de articulación política entre quienes vivían en territorio y quienes lo planificaban desde la administración.

Para el año 2011, se ejecutó el proyecto de las escaleras eléctricas que buscaron diezmar la presencia de actores ilegales de los barrios 20 de Julio e Independencias, mediante el fortalecimiento de la infraestructura vial como medio de inserción Estatal en una zona con altos índices de violencia. Al mismo tiempo, estas intervenciones permitieron tratar los problemas de movilidad de la comuna. Algunas dinámicas surgieron paulatinamente a la construcción de las escaleras eléctricas en los barrios aledaños ( 20 de julio y Las independencias), pues la ciudadanía comenzó a intervenir paisajísticamente los barrios aledaños a estas edificaciones como forma de expresión estética que respondía a la transformación física y social del territorio mediante el tratamiento de la memoria histórica como forma coercitiva del territorio (Peña, 2018).

En la actualidad, Medellín reproduce un modelo urbanístico cuyo objetivo principal es intervenir los territorios urbanos para desarrollar políticas sociales que atiendan las necesidades de la ciudadanía en aspectos de movilidad, seguridad y desarrollo económico
(Restrepo, 2012). De esta manera, surge desde la iniciativa local, la producción del pasaje de grafitis, que fue posible a partir de la pavimentación del viaducto de Las independencias, donde los muros fueron artísticamente intervenidos, con el objetivo de contar la historia de la Comuna 13 a través del grafiti, lo que mejoró el entorno para la movilidad de los ciudadanos en una zona rehabilitada y permitió conexiones con los medios masivos de transporte para dar paso a prácticas turísticas como el grafitour.

\section{Surgimiento del turismo en las coordenadas del modelo urbano de Medellín}

A pesar de las condiciones topográficas y sociohistóricas de la Comuna 13, el modelo Medellín ha buscado incentivar el sector de servicios turísticos, mediante proyectos de renovación urbana como mecanismos que permitían aprovechar el espacio público en función de un proyecto político de ciudad.

Ante este panorama, la Comuna 13, gracias a la presencia de las escaleras eléctricas y la zona de graffitis, comenzó a experimentar una dinámica turística que fue marcando los procesos de turistificación y mercantilización territorial en esta zona de la ciudad. La Comuna 13 es uno de los nichos turísticos por excelencia en la ciudad de Medellín (Alcaldía de Medellín, 2016) que presenta un importante flujo de turistas que recorren principalmente los barrios intervenidos: el 20 de Julio y Las Independencias, donde se encuentran las escaleras eléctricas y el Parque Biblioteca San Javier.

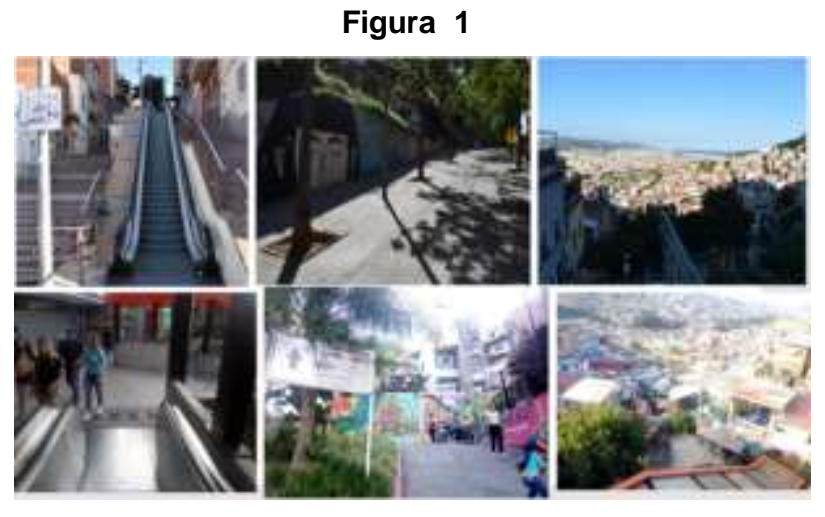

Intervenciones territoriales en El Carmel (arriba) y la Comuna 13 (abajo).

Durante el recorrido, los turistas pueden apreciar el arte urbano plasmado en las paredes de estos barrios, mientras acceden por la zona de ladera, que es atravesada por una escalera eléctrica de 5 tramos. En este contexto de desarrollo turístico, la intervención territorial en la comuna produjo un acelerado incremento (y surgimiento) de pequeñas economías informales que dan cuenta de la generación de prácticas que van desde 
la venta de frutas, platillos típicos de la comida colombiana hasta la venta de camisetas estampadas con los grafitis de las paredes de la comuna.

Por tanto, resulta relevante ahondar en las prácticas devenidas de las intervenciones territoriales en la comuna y sus efectos en la vida de las personas y en las percepciones que se transformaron a la par del territorio.

\section{Barcelona, el caso del Carmelo}

El Carmelo es un barrio ubicado en la ladera montañosa del distrito de Horta Guinardó en el costado suroriental de la ciudad de Barcelona. Los orígenes de este asentamiento se ubican a comienzos del siglo XVI como fruto de la expansión agrícola en fincas periféricas de Cataluña. Lo que se convertiría en el barrio El Carmel, siglos después, fueron zonas utilizadas para la producción agrícola que permitieron generar relaciones de poder y ubicar zonas de residencia conocidas como las Masías de Horta Sant Genis y las zonas Genis Dells Agudells y Sant Martín del Provecals (Pérez, 2018). Para el siglo XVIII, la zona agrícola de Horta se expandió a partir de la llegada de una población diversa. Para 1859, se ejecutó el plan de ensanche Cerdá, lo que promovió movimientos internos por parte de personas que se trasladaron hacia las zonas periféricas, fruto del impacto ocasionado por la transformación abrupta de Barcelona en su estructura tanto social como física (Pérez, 2018). El territorio urbano de la ciudad y del barrio el Carmelo fue reconfigurándose debido los desplazamientos humanos producidos por fenómenos de despojo de tierras y conflicto en la época de la guerra civil y a los movimientos migratorios de Asia, África y Latinoamérica que se fueron localizando en este barrio en difícil topografía, situado en una zona de colina con altas pendientes y desniveles.

A largo del siglo XX, Barcelona ha experimentado varios proyectos de trasformación urbana. Uno de los autores más destacados en materia de renovación urbana de Barcelona fue el arquitecto y planificador urbano Oriol Bohigas quien, en la década de los 80 , llevó a cabo una importante regeneración urbana que permitió a la ciudad modelarse como una ciudad ejemplar a nivel regional y global (Oliver, 2012). La apuesta de Bohigas, en cuanto a la transformación urbana de Barcelona, partía de la descentralización de la estructura urbana a partir de la iniciativa orientada a la creación de espacios locales, es decir, barrial. En este sentido, el urbanista señala que a Barcelona hay que entenderla como:

...un gran sistema coherente y racional, en el cual domina una especie de metafísica de la totalidad o entenderla desde la pieza relativamente autónoma del barrio (...), de las formas urbanas que han de posibilitar primordialmente la mejora de las condiciones de vida del usuario más inmediato. (Bohigas, 1997:14).

Esto refiere a que la política urbana barcelonesa giró, desde sus inicios, en torno a la renovación y regeneración a escala de barrios y distritos, permitiendo pensar en un urbanismo descentralizado que escapara de la lógica racionalista del plan Cerdá (conocido por su estructuración ordenada de las parcelas del distrito Eixample y Ciutat Vella). La propuesta de Bohigas permitió proyectar la ciudad para su edificación consensual, articulando la planeación con la participación democrática. Esto permitiría producir un urbanismo consolidado atravesado por la integración escalar tanto de barrios, distritos como la propia ciudad y el mundo. Para el arquitecto Miquel Domingo, era necesario consolidar la propuesta de Bohigas, en cuanto a la idea de descentralizar la ciudad como espacio orgánico y conectado desde su estructura periférica como centralizada, tal como lo señala el autor: "monumentalizar la periferia no es un gesto patern alista ni populista, sino una necesidad para reequilibrar Barcelona" (Domingo, 1998: 176).

Todas estas políticas de ciudad tuvieron un efecto en la configuración de El Carmelo, barrio que ahora está expandido en la zona de ladera de colina de la ciudad y que durante décadas tuvo problemas de accesibilidad y comunicación. Sin embargo, desde la década de los 80 , se implementaron mecanismos de intervención en el territorio, siguiendo la lógica de una ciudad conectada desde sus periferias y la centralidad a partir de los Planes Especiales de Reforma Interior (PERI) que buscaron diagnosticar la población para consolidar proyectos que permitieran integrar la ciudadanía con el resto de la ciudad desde las reformas en la infraestructura física de la urbe (Beltrán 2012 citado en Pérez, 2016).

Partiendo de las necesidades de la ciudadanía, el Ayuntamiento comenzó la ejecución de los planes urbanos, coherentes con la población mixta del Carmel. Para el año 2003, se inauguró la primera biblioteca del sector, conocida como Biblioteca Juan Marsé. Lo que se buscó con esta edificación, fue consolidar espacios de aprendizaje y recreación cultural para aquellos ciudadanos que, por sus condiciones de hábitat, no podían acceder a instituciones del conocimiento ya que les era imposible trasladarse desde la zona de ladera hasta las bibliotecas cercanas. De igual forma, las mejoras en el hábitat del barrio se plantearon de acuerdo a los planes estratégicos de intervención del territorio en materia de movilidad, infraestructura y conectividad. Por ejemplo, para el año 2005, Barcelona fue pionera en construir las primeras escaleras eléctricas en un entramado urbano, con el fin de mejorar la movilidad de sus ciudadanos. Fue así como se ejecu tó esta obra, seguida de la construcción de la lín ea 
5 del Metro de Barcelona. Posterior a ello, la cualificación del sistema de transporte de autobuses que se articulaba con las líneas del metro.

\section{Intervención del territorio en las coordenadas del Turismo}

El modelo de Barcelona se ha erigido como un proyecto que trató de consolidar un urbanismo igualitario en cuanto a la participación de sus ciudadanos en materia de planeación y proyección de ciudad. El modelo se ha convertido en una especie de marketing de ciudad cu yo objetivo ha sido incentivar el turismo como forma de captación de renta de la ciudad (Mansilla, 2016). En este sentido, Barcelona es hoy una de las ciudades más visitadas en todo el mundo. El turismo ha generado fenómenos a nivel territorial, económico y cultural en la ciudad, pues atraídos por ofertas laborales y educativas, los extranjeros fueron ocupando paulatinamente la oferta habitacional de los propios locales, lo que derivó en el surgimiento de especulación inmobiliaria, pues los propietarios de muchos apartamentos comenzaron a jugar con los precios de arrendamiento, producto de la oferta que incrementaba el turismo en muchas zonas de Barcelona.

Actualmente, habitar la zona centro de Barcelona es difícil, puesto que el acceso a los precios no se ajusta a los ingresos per cápita de buena parte de los viejos habitantes, promoviendo un proceso de segregación socioespacial reflejados en una paulatina movilidad de ciudadanos locales emplazados a barrios periféricos (Fernández, 2018).

Actualmente, el barrio tiene una población estimada de 31.377 habitantes, en su mayoría ascendientes de diversos procesos migratorios, determinados por momentos históricos tanto a escala regional-nacional como por los flujos de migrantes trabajadores, principalmente procedentes del norte de África y América del sur (Ayuntamiento de Barcelona, 2018). En este sentido, a pesar de que el barrio se encuentra en zona de ladera y presenta una morfología urbana regular, fragmentada por sus condiciones topográficas, los ciudadanos de este territorio siguen apostando por un urbanismo que ofrezca condiciones para satisfacer las necesidades de movilidad, que a pesar de contar con las escaleras eléctricas, estos proyectos van encontrando otros azares como lo es una población adulta que tiene que trasladarse diariamente hacia la ladera que constituye el barrio y en su defecto el distrito. De igual manera, se enfrentan al problema del turismo, como impacto de orden sociocultural, ya que interviene en las formas en la que la propia ciudadanía del Carmel comprende, vive y reproduce el barrio en una dinámica relacionada con la imagen de Barcelona ante el mundo (Ayuntamiento de Barcelona, 2018).
En este sentido, cabe destacar la zona de bunkers construidos en el barrio du rante la guerra civil española, por situarse en una zona estratégica para la lucha antiaérea entre las fuerzas militares y civiles que se oponían al ejercito fascista, los cuales en los últimos años se han convertido en uno de los escenarios más atractivos para los turistas y en un foco problemático para los habitantes del barrio por problemas de incivismo de tales visitantes (Polo, 2018).

\section{Ecos del territorio: un análisis de las percepciones frente a las transformaciones territoriales}

Las narrativas del territorio que se trabajan a continuación se encuentran enmarcadas en categorías analíticas que permiten desentrañar las percepciones en torno a las transformaciones territoriales que son: vida en el barrio, intervenciones territoriales, problemáticas asociadas al territorio, turistificación del espacio y la relación habitante-Estado.

En este sentido, a partir de la recopilación de la percepción de quienes producen el territorio, podremos ahondar la forma en la que las intervenciones actúan en palabras desde una dimensión de la política, es decir, lo que instaura un orden social a nivel de discurso (Mouffe, 2014; Laclaou, 2014). Así pues, las entrevistas no solo develan un aspecto empírico de la relación ciudadanoterritorio, permiten de igual forma comprender el inherente conflicto entre ciudadano y un orden social establecido desde todas las dimensiones que abarcan el sujeto como un actor político que interviene en el territorio.

Para fines prácticos se trabajará con las abreviaturas C13 para referirse a la Comuna 13 y BC para Barrio El Carmel.

\section{Vida en el barrio}

Contar el barrio es hacer un recorrido por la propia memoria del territorio, los habitantes expresan su experiencia como un transcurrir de hechos en el que reconocen el paso del tiempo en función de diferentes elementos de carácter territorial. Contar la vida en el barrio es a su vez reivindicar la narrativa social que permite entender la apropiación del espacio a partir de diferentes grupos sociales con un mismo entorno de vida, como se puede identificar en las siguientes narrativas:

Nosotros estábamos rodeados por los paramilitares, por la guerrilla y la policía. Habían enfrentamientos, esto era muerte, esto era todo, esto parecía un desierto, los enfrentamientos eran muy horribles, aquí muchos de nosotros perdimos nuestros seres queridos, acá todavía hay gente desaparecida, hay madres amigas mías que todavía en el momento no 
saben dónde quedaron sus hijos, ehhhhh (sic) ahora nosotros sí hemos mejorado mucho después de la operación Orión, y acá pues hubieron dos operaciones, o es lo que más se le menciona al turista ¿cierto? [...] vivir acá era como vivir en el desierto, debajo de las camas... esperando que cualquier bala lo matara a uno (C13. Vivian, 68).

Este barrio estaba hecho muchos años atrás por una serie de fincas que tenían, eran terratenientes, murieron los padres, los hijos empezaron a dividir por parcelas esos terrenos, empezaron a venderlas baratas, eran el boom de cuando veníamos muchos inmigrantes de Andalucía, de Galicia, etcétera, después de la guerra y aquí venían a trabajar y empezaron a construir de forma barata lo que se llaman "chabolas" y por eso esta desorganización de calles que hay aquí en este barrio, porque se construyó todo a la brava sin un plan urbanístico correcto... todo eso fue producto de migración [...] es un barrio que ha evolucionado a base de migración (BC. Jesús, 67).

Como se observa en estos testimonios, las maneras de narrar el espacio se diferencian; mientras que el caso de la $\mathrm{C} 13$ el discurso gira en torno a la atmósfera del territorio, es decir, de los procesos simbólicos relacionados al contexto de violencia que experimentó la C13, desde el recrudecimiento del conflicto armado a principios de la década de los dos mil, para el caso de $\mathrm{BC}$, el recorrido por la historia del lugar refiere, específicamente, a un proceso territorial, que explica el espacio y la configuración del barrio como resultado de un largo proceso nacido de la migración que permitió la producción de un barrio cuya configuración urbana se vio determinada por la condición geográfica que presenta el territorio donde se ubica el barrio.

Ambos testimonios parten del punto de vista particular de cada actor, que rescatan a través de las vivencias, los momentos que resultan trascendentales para narrar su entorno y la forma en que su relación con los otros y con el espacio se ha transformado a lo largo del tiempo. Estas miradas permiten situar los contextos previos a intervenciones en ambos lugares, que cómo ya se mencionó, tienen un origen en actores de intereses y objetivos distintos, pues el territorio puede ser intervenido desde el Estado y todo su aparato operativo, la sociedad civil organizada, el mercado o los grupos al margen de la ley, como el caso del narcotráfico, bandas de barrio o grupos guerrilleros.

\section{Intervenciones territoriales}

En el medio de un contexto socioterritorial problemático, existen diversidad necesidades que deben enfrentarse a nivel estructural. En los contextos que aquí se trabajan, las problemáticas son diversas, pero compartidas y se relacionan con aspectos de movilidad, accesibilidad, acceso a una vida libre de violencia, cobertura de servicios básicos y a la presencia de infraestructura para la cultura y el deporte.

Menos mal pusieron esas máquinas... [Refiriéndose a las escaleras eléctricas], porque la verdad yo no me imagino subiendo y bajando ahora que tengo $\mathrm{mi}$ problema de piernas y de cadera. Entonces sí, eh... antes de las escaleras eléctricas, moverse por el barrio donde uno nació era muy difícil y aburridor, uno ya ni quería ir al centro a hacer vueltas porque le daba pereza a uno bajar tantos escalones y uno tan viejo [...] No nada mijo, ellos creen que por mandar a los policías se nos van a acabar los problemas. Mire, pusieron esas escaleras y ni fu ni fa (sic). Los únicos programas que se realizan en la comuna los hacen en los parques biblioteca o si no por allá, en las JACii ¿Por acá, usted, cuándo ve un trabajador de la alcaldía preguntando cómo estamos? Me imagino que creen que bien, al ver turistas y todo eso, pero no (C13. Doña Salomé, 68). Una de las dinámicas, fueron como el mejoramiento de los hogares, o sea eran casas que eran como ranchitos o casi de otro material. Estamos hablando de obra negra y con la construcción de las escaleras eléctricas, empezaron a mejorar las casas porque claro, como venía el turista, no dejan que ¡uy no, van a ver mi casita feíta! Entonces arreglaron como las fachadas de las casas. $Y$ no solo las fachadas, algunas casas por dentro (C13. Nely, 47)

A mí me gusta ver que últimamente se está trabajando mucho en cultura. Hay muchos programas educativos, aunque tengamos a estos niños pidiendo plata allá arriba. Sin embargo, han estado adelantando varios programas, por ejemplo en la casa cultural, donde las verracas. También en el parque biblioteca San Javier, ahí estoy camellando (sic) en un proyectico con los raperos y los niños de San Javier [...] La imagen de los barrios está mejorando, aún tenemos problemas hay que decirlo, aún tenemos problemas, pero las cosas están cambiando lentamente para bien de la comunidad. Espero que, en el futuro, bueno cuando también tengamos una buena administración podamos cambiar muchas cosas de la comuna (C13. Juan, 63).

El caso de Medellín refiere a intervenciones que tenían el objetivo de solucionar problemas de movilidad, para lo que, en 2011 se construyeron cinco tramos de escaleras eléctricas que comunican la red de buses con la zona turística de Grafitour, esto como encomienda de los Proyectos Urbanos Integrales de la Comuna 13 PUI. Esta primera trasformación permitió mejoras en el paisaje urbano, como lo menciona uno de los testimonios que sucedió como una consecuencia de la mejora del espacio con fines turísticos y que los habitantes tienen presente como un hito en su comunidad. Sin embargo, el testimonio de Juan refiere a 
la insuficiencia de estas escaleras para transformar totalmente la vida de la comuna, pues hacen falta más tramos que funcionen para conectar todos los puntos del barrio. Sin embargo, hay problemas que los habitantes reconocen en el entorno y que no tienen que ver, específicamente con una intervención territorial, sino con un proceso contenido en el propio territorio.

La biblioteca dignificó un poco el barrio, o sea tener una biblioteca, parece una tontería, pero es como decir, vale, somos obreros, pero no somos analfabetos, nos gusta leer y nos gusta disfrutar de un espacio de tranquilidad... te dignifica un poco, porque para los demás es "mira tu barrio, cómo es que no tienes ni biblioteca" (BC. Aída, 36).

El sistema que han hecho ahora de autobuses en vez de acercarnos a la ciudad, parece que nos ha alejado, para ir a Plaza Catalunya tengo que coger dos autobuses y el hecho de coger dos autobuses da sensación de lejanía y da sensación de "me voy a otro lado" (BC. Montserrat, 57).

La orografía de este barrio la sufrimos en la propia carne, por lo que en este barrio hubo de las escaleras mecánicas y el transporte, fue para bien porque este barrio antes estaba muy desamparado y no teníamos nada en cuanto a infraestructura que agilizara la vida de las personas con la movilidad reducida o discapacitadas (BC. Pablo, 80).

Para el caso del Carmel, hay dos situaciones que se ven reveladas en los testimonios: una, la presencia de infraestructura de tipo cultural y la mejora en la movilidad a través del sistema de transporte urbano. La sola idea de tener acceso a una biblioteca genera apropiación en cuanto al territorio como espacio de conocimiento en el que se puede aprender e interactuar con otros vecinos y a través de la cual, la propia ciudadanía "se dignifica y dignifica" al barrio. Por otra parte, en el sentido de la movilidad hay percepciones contradictorias, mientras se reconoce un avance en la forma de moverse en la ciudad y en el propio barrio, también se señala la falta de cobertura y comodidad en los trayectos, pues la ubicación del Carmel demanda una red de transporte que responda a las necesidades de quienes lo habitan y no sólo de quienes lo transitan o de la población flotante venida del flujo turístico en la ciudad de Barcelona.

Ambos escenarios presentan similitudes, los habitantes son capaces de identificar los efectos de las intervenciones, pero también las falencias que existen en el territorio y que lo trascienden, es decir, que ocurren dentro del territorio, pero que suceden como procesos simbólicos asociados a diversas problemáticas urbanas.

En el caso de Medellín, la evidencia sugiere que se implementó un modelo enmarcado en los postulados del urbanismo social con fines de mitigar la atmósfera de violencia con la que se asociaba a la comuna 13 , mientras que en el Carmel las transformaciones van en función de las exigencias ciudadanas para mejorar la movilidad en el barrio y hacer frente a los cambios venidos de la migración, el envejecimiento de la población y el turismo creciente.

\section{Problemáticas asociadas al territorio}

Existen problemáticas territoriales independientes a las intervenciones de los actores en el territorio, que muchas veces anteceden a una gran transformación o a veces, incluso, sobreviven a ella. A continuación se presentan testimonios relacionados a situaciones 0 hechos que los habitantes de ambos lugares perciben como problemáticas actuales y que dan cuenta del proceso continuo de transformación territorial.

...Esa relación, por lo mismo que te estaba contando, yo les decía, ¿pero en verdad ustedes trabajan? Me daba ganas de... ¿cómo te pego? Pero hemos visto, por ejemplo, que sencillamente, desde que existen las escaleras y el Grafitour tenemos un mínimo de paz y ahora con ellos (turistas) viviendo acá es mucho más fácil. Es más diverso, imagínate. Uno ya puede relacionarse no solamente con los vecinos del barrio sino con los otros, los que vienen de muy lejos (C13. Emir, 28).

Bueno, en este momento yo veo que la comuna 13 es un territorio que sigue con muchas problemáticas que están enfocadas en ciertas zonas que ni siquiera la alcaldía llega para apoyar, por ejemplo a proyectos que no tienen plata, están sin nada... (C13. Clara Wolf, 33 ciudadana alemana y habitante de la comuna 13).

$\mathrm{Si}$ uno ve que el abandono del estado es muy evidente. Uno ve que la gran mayoría, que el $85 \%$ de la gente, lo que es el 20 de Julio y las independencias tienen problemas que van de fondo, uno ve que tienen problemas de educación sexual o si, de concientizar a la gente de no tener al chino, pues como cuando uno tiene 16, 17 o 18 años, uno ve mucho eso, los niños trabajando... Una vez, una señora me dijo: "bueno yo ¿cómo le digo a mi niño que no me traiga esos 10 mil pesitos que se mendiga en la calle, porque eso me puede conseguir una bolsa de leche o una bolsa de carros? entonces, eso por un lado, el extranjero no sabe lo que es (C13. Juan L, 29).

En términos generales, lo que se infiere de estas percepciones es que existen problemas, como la cobertura de los proyectos urbanísticos en los asentamientos periféricos, la inseguridad y un asunto de desocupación infantil y juvenil. Este último, provoca que existan jóvenes y niños pidiendo dinero a los turistas, lo que refleja un problema más profundo, relacionado con las condiciones de vida de las personas en situación 
vulnerable, que encuentran en el turismo una oportunidad para conseguir recursos.

Como se recupera en estos testimonios, el turismo aparece como una salida "fácil" a un problema estructural, en el que la presencia del Grafitour puede significar una dinámica de doble rostro, es decir, uno en el que resulte positivo para las personas que logran obtener recursos informales de estas prácticas y solventar gastos de la vida diaria y otro, en el que la necesidad de educarse sea aplazada o eliminada porque habrán aprendido cómo obtener dinero sin una preparación.

Por otra parte, el asunto de la violencia nacida de la presencia del narcotráfico se ve aparentemente superada, pues no es un discurso que emerja para describir el presente de la vida en la comuna; sin embargo, aparece como una huella de la situación del pasado que durante años definió la vida en la zona y la forma en la que la $\mathrm{C} 13$ era percibida no sólo por sus propios habitantes, sino a nivel de la ciudad.

Encuentro el barrio envejecido, las aceras, fatal; las calles, fatal; está como viejo, como deteriorado, solo hacen parches, parque aquí, parche allá, pero nunca se acaba de arreglar y yo creo que el barrio necesitaría una buena reestructuración y un buen arreglo a nivel de calles y aceras (BC. Montserrat, 57).

Aparte de los servicios sociales, hay poca vigilancia; yo tengo mi nieto que ha empezado la ESO y no lo dejamos ir solo... va su padre a buscarlo o voy yo, pero solo no, viene ahora: desapareció un niño y no lo encuentran, una señora salió a sacar el perro y no volvió, ¿qué es esto? ¿Dónde vamos a llegar con esto? Yo quisiera que la señora Colauiii me lo dijera (BC. Isabel, 65).

Se nos está echando de mi barrio, se nos está echando a toda la gente de Barcelona joven, te estoy hablando de 550 euros un alquiler, se te acaba el contrato y te lo suben a 870 , pues lo siento mucho, pero para eso, me compro un piso y pago una hipoteca (BC. Aida, 36).

Las situaciones que los vecinos del Carmel ubican como problemáticas, refieren a la cobertura de servicios, estado del paisaje urbano, seguridad y especulación inmobiliaria. Existe un claro reconocimiento de quién es la autoridad y cuáles deberían ser sus funciones en la gestión del barrio, se da cuenta, también de la presencia organizada de grupos de vecinos que luchan por denunciar y resolver las problemáticas del barrio.

Los testimonios permiten ubicar problemáticas similares en ambos contextos. Sin embargo, algunos discursos sugieren la presencia de diferencias sustanciales, la principal de ellas, es la especulación in mobiliaria que en el caso de el Carmel se evidencia como un problema grave para la comunidad, que no sólo tiene que ver con los precios en los alquileres o del suelo en el barrio, sino con un efecto demoledor en la construcción de una dinámica vecinal entre quienes habitan el Carmel.

Por su parte, la Comuna 13 da cuenta de la presencia de niños y adolescentes en situaciones de riesgo que no son las mismas que se dan en el barrio catalán. Estas diferencias se explican dadas las historias de cada uno de los lugares y los problemas localizados en América Latina y el continente europeo.

\section{Turistificación del espacio}

Es importante mencionar que se identifica un contexto compartido por ambos espacios, que tiene que ver con el proceso de globalización que deviene en el surgimiento de problemáticas o situaciones que se replican en diferentes espacios sociales, como es el caso de la mercantilización del territorio a partir del fenómeno del turismo.

En tal sentido, el turismo aparece como una dinámica propia de la globalización que evidencia los límites del territorio y las consecuencias positivas y negativas a partir de su práctica en ciudades que apuestan por la rentabilidad de convertir al territorio en un espacio para ser consumido, situación que puede ser observada en los casos que competen a esta investigación.

Los vándalos ahora la piensan, no crean. Creo que eso de tener turistas y policía obedece más al turismo. Pero como le digo, ¿por qué no hay eso en otros barrios? Yo me imagino que si hubiera, la comunidad entera de la comuna 13 se beneficiaría. Mientras tanto, no lo hacen (C13. Juan $R, 76$ ).

Yo encontré este barrio, la comuna 13, un día, para hacer el tour y me acuerdo que me encantó el ambiente, la gente que encontré y más tarde, yo me dije que sería una buena experiencia de quedarme por acá y aprender y compartir con la gente que vive acá; su vida y toda la experiencia que puedo encontrar por acá. Rápidamente, descubrí una parte muy positiva de este lado, que quiere mostrar (C13. Emir, 28).

Entonces yo también le decía; no, es que usted es una verracaiv, entonces ahí empezó el nombre de las verracas. Entonces le dijimos: por qué no se pica unos manguitos y se pone a vender aquí; venga y verá, usted empieza. $Y$ empezó, todo el mundo como a sacar, y empezó a verse, o sea que era rentable que usted en su propio barrio o aun afuerita de tu casa te podías ganarte tu sustento, pues súper bueno. Y cuando entonces comenzó lo del Grafitour fue mejor, porque entonces la gente dijo: Valla [pintar en el barandal] para las escaleras y vienen que hacen unos grafitis súper lindos (C13. Nely, 47). Pues si usted mira, el turismo está acá por el grafiti, eso ha movido mucho la vaina con respecto al dinero, muchos eventos culturales organizados por los mismos turistas, por ejemplo, ya uno los ve, 
viviendo por acá, caminando como pedro por su casa. Es curioso, porque eso, hace unos diez o quince años no se veía, todos esos monos paseando y compartiendo con la gente (C13. Juan, 28).

Las voces ciudadanas en torno al fenómeno del turismo en la comuna 13 son dicotómicas. Por un lado, consideran la parte benéfica del turismo y las posibilidades que esta práctica da para generar espacios de trabajo informal y, al mismo tiempo, tener un espacio más seguro y vigilado. Los grafitis forman una parte fundamental en el imaginario comunitario para entender su territorio como un espacio turístico, que comenzó de manera reciente debido a un proyecto de ciudad que apuesta por el turismo como un eje para la reactivación de la economía en un contexto como el colombiano, en el que la violencia tuvo efectos sobre la visión que el mundo tenía el país.

Ahora está viniendo gente de fuera, porque ciutat vella y todos estos sitios, con el tema del turismo, están encareciendo los alquileres, porque las cadenas estas de airbnbv están alquilando pisos turísticos y a los propios vecinos del barrio les están encareciendo (BC. Jesús, 67).

En los últimos tiempos, han rehabilitado los restos de las baterías antiaéreas que están aquí cerca a los que vienen bastantes turistas y crean algunos problemas con los vecinos [...] Ahora vienen muchos turistas jóvenes y acaban haciendo botellón hasta altas horas y haciendo ruido, la que era una zona súper tranquila, pues ahora tiene problemas (BC. Marco, 35).

Los bunkers han estado dando una serie de perjuicios a los vecinos por la gente incívica que viene y no sabe comportarse, turistas que vienen a subir arriba al botellón, a dejar los excrementos y orines... en verano aquello es un festival (BC. Pablo, 69).

El turismo en el barrio el Carmel, es distinguido como un flagelo del gran turismo de ciudad que tiene Barcelona, pues al lugar acuden turistas que se dirigen a los bunkers, las baterías antiaéreas del período franquista. Este espacio fue recuperado de manera aislada, es decir, que no se ha producido una infraestructura de soporte para que el barrio pueda mitigar los efectos de las demandas de un espacio turístico dentro del territorio urbano. Los vecinos reconocen a las prácticas que se dan allí como "turismo de botellón", ya que los bunkers son utilizados para beber alcohol en la vía pública y permanecer en el lugar a deshoras, generando problemas de ruido, para los vecinos de la zona.

Los casos anteriores denotan las prácticas sociales de dos grupos antagónicos, los afectados y los beneficiados por la práctica turística en diversas dimensiones y niveles. Mientras que ésta resulta una actividad que deja beneficios económicos, es un fenómeno que debe ser contenido para evitar estragos negativos. Por ejemplo, fenómenos como la gentrificación, que se produce usualmente en zonas con bajos costos de rentabilidad, lo que permite especular con los precios de venta al mejor postor, en este caso el turismo. Sin embargo, lo que hemos visto de igual forma es contingencia ciudadana ante problemáticas de comoditizacion del espacio urbano, en el que el desarrollo, por ejemplo tanto en Medellín como en Barcelona, está sedimentado en la idea del turismo como forma de valorización del espacio urbano de estas dos ciudades (Harvey, 2012: 106).

\section{Relación habitante-Estado}

La percepción ciudadana, en torno al Estado, es un aspecto esencial que se debe tener en cuenta para una mirada contextualizada de las evidentes trasformaciones territoriales tanto a nivel barrial como a nivel de ciudad. Tal como lo mencionan sus habitantes.

.... Incluso como guía le dicen a uno, como bueno, ¿usted cuál cree que es la solución? ¿Cuál es la causa de eso? Pero no hay una causa de toda la problemática que estamos viviendo allá. No hay una causa ni hay una solución, eso es algo global, uno ve que todavía, si la gente va, toma las fotos, pero lastimosamente, yo lo digo, con mucho respeto, eso es como cuando uno va al zoológico que sí, que la fotico (sic) y hasta luego chao. Aquí hay un problema aún muy grande de desnutrición, de falta de acompañamiento a los padres de familia, aún hay muchísimos niños que aún no estudian y contienen el acompañamiento de los padres, precisamente porque nosotros vivimos en Colombia y a uno le toca salir a rebuscarse (C13. David, 28).

El turista viene, ellos graban, se llevan las grabaciones de los negocios, mejor dicho, lo muestran en los rincones del mundo que usted quiera. Lo arman, le graban, una cosa y la otra, pero... ¿en qué nos beneficia eso? Sí, a veces nos graban y nos toman fotos y ni si quiera nos prueban el producto, ni si quiera por agradecimiento; ve que chévere, gente que está trabajando. Lo mismo que hizo el alcalde, qué día, vinieron 50 y tantos alcaldes de otra parte y qué hicieron esos 15 días acá, en vez de sentirse orgulloso y mostrarnos como gente trabajadora, gente que quiere superación, vino y nos hizo tumbar todos los puesticos de trabajo, como el que dice una madre "oculta su hijo feo", eso ha hecho el alcalde con nosotros (C13. Vivian, 68).

Me parece horrible eso que otras personas no se beneficien, porque mire a su alrededor, falta muchísimo por parte del Estado en este barrio, en esta comuna. Hay casas que cuando llueve se caen, se va el agua mucho, eso no se ha arreglado y hasta 
que realmente la alcaldía arregle eso no va a estar bien (C13. Salome, 68).

La concepción ciudadana en la $\mathrm{C} 13$ respecto al papel del Estado es de inconformidad. Si bien la reciente presencia del Estado obedece a las dinámicas turísticas, y estas han beneficiado un sector de la comuna en cuanto al tema de seguridad, hay problemáticas de índole social que aún no han sido satisfechas. Esto ha producido en la ciudadanía de la C13, una percepción utilitarista por parte del Estado, quien recurre a su presencia con el objetivo de perpetuar las dinámicas económicas fruto del turismo y el modelo de ciudad.

Las escaleras aún no funcionan, eso es una vergüenza, y la señora Colau mucho de aquí (señala su cabeza) y poco de hacer, eso es lo que hace la señora Colau... (BC. Isabel, 65).

A mí me gustaría preguntar ¿qué quiere el ayuntamiento de Barcelona del Carmelo? o ¿qué le pide o qué papel le da dentro de la política del ayuntamiento de Barcelona?, quizá la pregunta tendría que ser al revés, quizá sería más interesante... Si a Gracia se le pone tanto esmero, pues que al Carmelo se lo ponga lo mismo, porque pagamos los mismos impuestos. No me gustaría que mi barrio se perdiera, no me gustaría para nada que se hiciera la zona de los tres Turonsvi, que me parece que sería cargarse un barrio (Montserrat, 57).

El Carmelo tiene las afectaciones de los Tres Turons, también tiene un plan urbanístico que quieren derribar muchas casas (BC. Aida, 36).

Por los autobuses luchamos mucho, trabajamos mucho en cuanto a adaptar los autobuses a que fueran factibles para las personas con discapacidad [...] El movimiento vecinal aquí en este barrio ha luchado mucho, esto eran calles sin asfaltar, sin iluminación, sin servicios... [...] La asociación de vecinos del Carmelo ha ido a menos (BC. Pablo, 64).

Por su parte, el Carmel presenta la misma concepción en torno al papel del ayuntamiento, en cuanto al abandono de algunas problemáticas sociales vigentes en el barrio. A esto se suma la poca intervención del Estado en materia de la especulación inmobiliaria que se viene presentando y la iniciativa del macroproyecto para la creación de un parque emplazado en la zon a de los Tres Turons, que implicaría el derrumbe de casas y el desalojo de una considerable cantidad de habitantes, lo que supone efectos en el tejido social del barrio.

Sin embargo, resulta conveniente distinguir que existe una noción de la organización comunitaria, que los vecinos del barrio reconocen la presencia de grupos organizados de vecinos y son conscientes de su papel en la gestión de los asuntos del barrio. Este aspecto es fundamental a la hora de entender la consolidación de un territorio urbano desde el trabajo político de sus comunidades. Como se ha observado, la organización barrial atraviesa todos los componentes de la cotidianidad, reflejadas en quejas, propuestas y soluciones producto de la movilización de una ciudadanía consciente de su entorno.

\section{Conclusiones Discusión de resultados}

Este ejercicio ha permitido reconocer la existencia de una dinámica global que tiene efectos en el territorio a nivel local, y la presencia de problemas o situaciones similares alrededor del mundo que se insertan en estas dinámicas económicas y políticas, cuyos impactos adquieren verdadera importancia en la vida de las personas y visibilizan las relaciones de poder y los roles que juega la ciudadanía, el Estado y los grupos de poder económicos.

Estas dinámicas son explicadas desde el fenómeno de la globalización que supone una interdependencia y vinculación entre Estados y sociedades del mundo, en el que las consecuencias de las decisiones gen eradas en un sitio, influyen en otro, dada la integración de los mercados mundiales en los intercambios comerciales actuales (Sánchez, 2015), situación que impone una nueva lógica en la vivencia del espacio y que requiere aproximaciones diversas para su explicación.

Este trabajo recupera las narrativas del territorio por parte de los sujetos que reafirman que las percepcion es juegan un papel fundamental en la construcción del territorio, determinan la producción de un imaginario y de una memoria colectiva que no pueden modificarse con la misma velocidad con la que se modifica el territorio.

Las huellas de la violencia, en el caso de Colombia y la experiencia de los cambios en la infraestructura y la turistificación del espacio en Barcelona, dan cuenta de la presencia de los hechos en la memoria colectiva que permanece, se socializa y trasciende al propio territorio. Las similitudes entre ambos lugares refieren a su emplazamiento como barrios periféricos de ladera, que atravesaron transformaciones territoriales de gran escala en su historia reciente. La morfología del territorio tiene un impacto en la movilidad y accesibilidad a los lugares. Ambos sitios comparten una tradición de "vida barrial" que los identifica como miembros tanto de El Carmel como de la Comuna 13. Análogamente, estos asentamientos se encuentran en ciudades que se han turistificado en los últimos años y cuyos efectos han irrumpido en sus prácticas cotidianas.

Las prácticas turísticas son resultado de la intervención en el territorio desde una lógica mercantil que impacta en los modelos urbanísticos de las ciudades donde se emplazan nuestros casos de estudio que han generado escenarios de conflicto social entre quienes producen el 
territorio y quienes lo ocupan a manera de consumo. La teoría sugiere reconocer el fenómeno de la gentrificación y los testimonios recuperados en el trabajo en el Carmel, dan cuenta de la presencia real de esta situación que no sólo encarece el suelo de la zona sino que debilita los lazos vecinales a través de la expulsión de habitantes. Rojas (2016) menciona que en los recintos gentrificados abundan los conflictos que no son sólo de carácter territorial, también son una especie de guerra simbólica entre el espacio real y el espacio turístico que implica una construcción fantasiosa del territorio que facilita y define los mecanismos para la gentrificación. La copresencia de turistas y residentes son lo suficientemente agresivas para generar confrontaciones profundas en el entorno urbano, que como lo sugieren Hiernaux y González (2014), van a convertir al conflicto en una variable importante para explicar el fenómeno de la gentrificación.

En el sentido de lo simbólico, es de reconocer que el territorio encarna la lucha por la acumulación del capital y ha estado siempre en disputa, en la reconfiguración de la geografía urbana ha traído consigo cambios a nivel territorial y en el estilo de vida de los habitantes, en el que la calidad de la vida urbana es una mercancía para quienes tienen dinero, en la que "las actividades culturales y basadas en el conocimiento, así como el continuo recurso a la economía del espectáculo, se han convertido en aspectos primordiales de la economía política urbana" (Harvey, 2012: 34).

Por otra parte, las diferencias fundamentales surgen de los contextos nacionales y regionales en donde se ubican sus territorios: La comuna 13 y El Carmel. Por un lado, la comuna 13 es un barrio con inmigrantes nacionales fruto del conflicto armado colombiano y por otro, El Carmel, barrio cuya dinámica tanto poblacional como de territorio ha sido transformada por fenómenos de migración que en un principio sucedió desde otras regiones de España y que ahora recibe a migrantes internacionales.

En este sentido, la producción especial de los barrios se diferencia en tanto a los objetivos que subyacen en dichas intervenciones. Por un lado, en la Comuna 13, la intervención urbana sucedió bajo una lógica de seguridad, mientras que en el Carmel, las intervenciones han sido hechas para mejorar la accesibilidad y la movilidad en el territorio en un diálogo entre ciudadanos y ayuntamiento.

Los problemas del territorio siguen siendo de carácter material y han de trabajarse desde lo local. La primera instancia, que los habitantes de ambos lugares reconocen como responsable de la gestión del territorio, es el ayuntamiento, por lo que resulta fundamental reflexionar sobre el papel de este nivel de gobierno en la gestión del territorio.
A la par, se tendría que reflexionar sobre el papel de la ciudadanía en la transformación de su propio territorio y en la gestión de los problemas de su entorno, pues en los casos estudiados se observa una diferencia entre la vivencia de la ciudadanía organizada, que es más marcada en el caso del Carmel, pues existe una noción de vecino como sujeto político, mientras que en el caso de la Comuna 13, la organización vecinal no está consolidada.

Al respecto, ya lo señala Castells (2013), existe la necesidad de una ciudadanía organizada para la conquista de las renovaciones urbanas, pues las reivindicaciones ciudadanas sólo pueden triunfar si se transforman en un movimiento social estrechamente vinculado a la lucha política.

Finalmente, a través de este ejercicio se puede concluir que el análisis de los fenómenos territoriales es, por fuerza, de naturaleza social. Por ello, las narrativas sobre territorio se vuelven fundamentales para reconocer cómo se experimenta la modificación del espacio y cuáles son las consecuencias de habitar un mundo globlalizado que sigue teniendo en el territorio un ancla a la realidad.

\section{Referencias}

Alcaldía de Medellín (2004). "Medellín, Compromiso de toda la ciudadanía" https://www.medellin.gov.co/irj/portal/medellin

Alcaldía de Medellín (2008) "Medellín Solidaria y competitiva" https://www.medellin.gov.co/irj/portal/medellin

Alcaldía de Medellín (2011) "La transformación de Medellín" https://www.medellin.gov.co/irj/porta1/medellin

Alcaldía de Medellín (2016) "Perfil demográfico 2016-2020. Comuna 13 San Ja vier" https://www.medellin.gov.co/irj/portal/medellin

Almirón, Ana lía (2004). "Turismo y espacio. Aportes para otra geografía del turismo" en Espaço e Tempo. Vol 1. No. 16, pp. $166-180$ https://www.researchgate.net/publication/2855646

Alvear, David. (2015). La pugna por el espacio urbano: la transformación de Medellín 2004-2014. Tesis de maestría. Barcelona: Universitat de Barcelona.

Aricapa, Ricardo (2016). Medellín es así. Un clásico del género periodístico. Bogotá: Ediciones B.

Arreola, Arturo y Saldívar, Antonio (2017). "De Reclus a Harvey, la resignificación del territorio en la construcción de la sustentabilidad". Región y Sociedad. Vol. I, Núm. 68, pp. 223 257. http://www.scielo.org.mx/pdf/regsoc/v29n68/1870-3925regsoc-29-68-00223.pdf

Atehortúa, Clara.; Sánchez, Luz \& Jiménez, Blanca (2019) "El conflicto armado afecta todas las esferas. Implicaciones del conflicto armado en la comuna 13" en Revista de Derecho Vol. I, núm. 32, pp. 116-138.Bogotá: Universidad del Norte.

Avendaño, Isabel (2010). "Un recorrido teórico a la territorialidad desde uno de sus ejes: el sentimiento de pertenencia y las identificaciones territoriales" Intercambio, vol. I, núm. 8 pp. 1335. San José: Universidad de Costa Rica.

Ayuntamiento de Barcelona (2018). "Estadística i Difusió de Dades" https://www.bcn.cat/estadistica/castella/dades/inf/lecpadro/lec18/ p337.htm

Bauman,Zygmunt (2001) La Globalización: consecuencias humanas. México: Fondo de Cultura Económica 
Bauman, Zygmunt (2003) Modernidad líquida. México: Fondo de Cultura Económica.

Briceño, Morella y Gil-Scheuren, Beatriz (2005). "Ciudad, imagen y percepción". Revista Geográfica Venezolana Vol. I núm. 46, pp. 11-33 Redalyc, https://www.redalyc.org/articulo.oa?id=347730348005

Capel, Horacio (1973). "Percepción del medio y comportamiento geográfico". Revista de geografía. Vol. I, núm. 7, pp. 58 -150. Barcelona: Universitat de Barcelona.

Capel, Horacio (2016). "Las ciencias socia les y el estudio del territorio". Revista Bibliográfica de Geografía y Ciencias Sociales. Vol. 1 Núm. 21, pp. 1-38. http://www.ub.edu/geocrit/b3w-1149.pdf

Castells, Manuel (2013 [1973]). Movimientos sociales urbanos. México: Siglo XXI.

Centro de Estudios Urbanos y Ambientales (2014). Proyecto Urbano Integral PUI Comuna $13 \mathrm{http} / / /$ www.eafit.edu.co/wuf/guiamedellin/paginas/pui-comuna-13.aspx\#.XcrDtVdKjIU

Chivallon, Christine (2008). L'espace, le réel et l'imaginaire: a-t-on encore besoin de la géographie culturelle?, Annales de Geographie, V.1 Num.117, pp. 67-89.

Crespi, Montserrat y Mascarilla, Óscar (2018). "La transformación y gentrificación turística del espacio urbano. El caso de la Barceloneta (Barcelona)" Eure. Vol. 44, núm. 133, pp. 51-70 https://scielo.conicyt.cl/scielo.php?script=sci_arttext\&pid=S0250 $-7161201800030005$

Cuenca, Tatiana y Giraldo, Federic (2017). Memoria y transformaciones territoriales en la comunidad de las Casitas: un recorrido por los impactos de la minería de carbón en el sur de La Guajira. Bogotá: CINEP

Fonseca, Andrea (2011). "Las periferias en disputa. Procesos de pobla miento urba no popularen Medellín" en Estudios Políticos. vol. I, núm. 23, pp. 148-170.

Garay, Alfredo (2001). Algunas observaciones respecto a cómo el capital está reorga nizando nuestro territorio. En F. Carrión (Ed), La ciudad construida (p.199). Quito. Flacso.

González, Cristina (2018). Gentrificación y turismofobia: el caso de Barcelona. Trabajo de grado. León. España.

Gorenstein, Silvia (2015). "Transformaciones territoriales contemporáneas: Desafíos del pensamiento latinoamericano" EURE (Santiago), Vol. 41, núm. 122, pp. 5-26. Santiago: Pontifica Universidad Católica de Chile. https://dx.doi.org/10.4067/S0250-71612015000100001

Haesbaert, Rogerio (2007). El mito de la desterritorialización "del fin de los territorios" a la multiterritorialidad. Río de Janeiro: Bertrand Brasil.

Harvey, David (2012). El enigma del capital y la crisis del capitalismo. Madrid: Akal.

Harvey, David (2012b). Ciudades rebeldes. Del derecho a la ciudad a la revolución urbana. Madrid: Akal.

Hiernaux, Daniel y González, Carmen (2014). "Turismo y gentrificación: pistas teóricas sobre una articulación". Revista de Geografía Norte Grande, Vol. I núm.58, pp. 55-70. México: Universidad Autónoma de Querétaro https://scielo.conicyt.cl/pdf/rgeong/n58/art04.pdf

Laclau, Ernesto (2014) Los fundamentos retóricos de la sociedad. Buen os Aires. Fondo de Cultura Económica.

Lynch, Kevin, (2008 [1969]), La imagen de la ciudad, Barcelona, España, Editorial Gustavo Gil.

Mansilla, José (2016). "Urbanismo, privatización y marketing urbano. La Barcelona neoliberal a través de tres ejemplos". Encrucijadas. Revista crítica de ciencias sociales. Vol. 11, núm. 102 pp. 1-18. http://www.encrucijadas.org/index.php/ojs/article/view/253

Marcús, Juliana, Mansilla, José, Boy, Martín, Yanes, Sergi y Aricó, Giuseppe (2019). La ciudad mercancía. Turistificación, renovación urbana y políticas de control del espacio público. Buenos Aires: Ministerio de Cultura de la Nación.

Milano, Claudio (2018). "Overtourism, malestar social y turismofobia. Un debate controvertido". Pasos. Revista de Turismo y Patrimonio Cultural. Vol. 16, núm. 3, pp. 551-564 http://www.pasosonline.org/Publicados/16318/PS318_01.pdf

Montoya, Nataly (2012). “EL Urbanismo social: Las Tácticas de un Estado Anfibio”. Bitácora Urbano-Territorial. Vol. 1, núm. 24, pp. 159-164. Colombia: Universidad Nacional de Colombia.

Mouffe, Chantal.(2014). Agonística: Pensar el mundo políticamente. Buenos Aires. Fondo de Cultura Económica.

Oliver, Cristina. (2012). Repercusión de la transformación urbana en la Regeneración Social del Barrio del Carmel. Proyecto Final de Máster. Barcelona: Universidad de Barcelona.

Peña, María (2018). La lúdica a sociada al Grafitour como forma de recuperación de la memoria en la Comuna 13 de Medellín. Tesis de maestría. Bogotá: Universidad del Externa do Colombia.

Pérez, Rocío (2018). La plaza del Carmel. Análisis del espacio público. Proyecto Final de Máster. Barcelona: Universidad de Barcelona. Facultad de Bellas Artes.

Polo, José (2018). "Los problemas de incivismo se extienden al Turó de la Rovira". La vanguardia. Recupera do 6 de Agosto de 2018. https://www.lavanguardia.com/local/barcelona/20180806/451235 921390/turo-de-la-rovira-bunkers-carmel-incivismo.html

Rayón, María (2018). "La globa lización: su impacto en el Estado-Nación y en el Derecho" Revista Jurídica Derecho, Vol. 7, Núm. 8, pp. 19-37. México: Universidad Nacional Autónoma de México. http://www.scielo.org.bo/scielo.php?script=sci_arttext\&pid=S24 13-28102018000100003\&lng=es\&tlng=es.

Rojo, Félix. (2016). "La gentrificación en los estudios urbanos: una exploración sobre la producción aca démica de las ciudades". Cuadernos Metropolitanos. Vol. 18, núm. 37, pp. 697-719. Brasil: Pontificia Universidad Católica de São Paulo http://dx.doi.org/10.1590/2236-9996.2016-3704

Sánchez, Verónica (2015) “La gestión local como propuesta para la solución de problemas comunes de urbanismo en América Latina". Panorama Vol.9. Núm. 16, pp. 92-103.

Sassen, Saskia (2001). La ciudad global. Nueva York, Londres, Tokyo. USA: Princeton University Press.

Serrano, Leticia (2015). Espacio público: realidad y percepción. Ocho plazas relevantes de la provincia de Alicante. Tesis de doctorado. Alicante: Universidad de Alicante.

Sonderéguer, Pedro (2012). La cuenca del Matanza-Riachuelo:notas sobre la cuestión urbana en Buenos Aires. Buenos Aires: Ediciones cooperativas.

Vergara, Alfonso y De las Rivas, Juan (2004). Territorios inteligentes. Madrid: Fundación Metrópoli.

Zenteno Torres, Elizabeth (2018). "La percepción del espacio urbano.El aporte de los mapas perceptivos al análisis del barrio ZEN de Pa lermo (Italia)". Revista INVI, vol. 33, núm. 93 pp. 99-122. https://dx.doi.org/10.4067/S0718-83582018000200099

\section{Notas}

\footnotetext{
${ }^{\mathrm{i}}$ Esta discusión es propuesta por la geógrafa francesa Christine Chivallon (2008) al reconocer la movilidad y discontinuidad expresada en el territorio.

ii Junta de Acción Comunal, que son organizaciones vecinales que trabajan a nivelde barrio para demandar problemáticas locales que existen a lo largo del territorio colombiano.

iii $\mathrm{Al}$ momento de la entrevista, Ada Colau funge como la alcaldesa del municipio de Barcelona, cargo que ejerce dese 2015
} 
iv Vocablo utilizado para definir a una mujer resiliente.

${ }^{v}$ Es una iniciativa digital que permite arrendar habitaciones y casas al mercado turístico cuya presencia se ha extendido a más de 90 países, es una plataforma sumamente criticada por la forma en la que opera en el mercado inmobiliario y turístico por los efectos que tiene en los precios de la renta y alquiler y en el desarrollo de la industria hotelera tradicional.

vi El parque de los Tres Turons se emplaza en los distritos de HortaGuinardó y Gracia de Barcelona. El actual ayunta miento encabezado por Ada Colau ha convocado a un proyecto de rehabilitación con serias implicaciones medioambientales. 